\title{
Synthesis of Fluorinated Alkyl Aryl Ethers by Palladium-Catalyzed C-O Cross-Coupling
}

\author{
Robert Szpera, Patrick G. Isenegger, Maxime Ghosez, Natan J. W. Straathof, Rosa Cookson, \\ David C. Blakemore, Paul Richardson, and Véronique Gouverneur*
}

Cite This: Org. Lett. 2020, 22, 6573-6577

Read Online

\section{ACCESS \\ 山ll Metrics \& More \\ Article Recommendations \\ Supporting Information}

$$
\begin{array}{r}
\mathrm{Rr}+\mathrm{HO} \sim \mathrm{R}_{\mathrm{F}} \frac{{ }_{\mathrm{B} \text { BuBrettPhos } \mathrm{Pd} \mathrm{G}(1 \mathrm{~mol} \%)}^{\mathrm{Cs}_{2} \mathrm{CO}_{3}(1.5 \text { equiv. })}}{\text { toluene, } 80^{\circ} \mathrm{C} \text { or } 100^{\circ} \mathrm{C}, 0.5-2 \mathrm{~h}} \\
\mathrm{R}_{\mathrm{F}}=\mathrm{CF}_{3}, \mathrm{CF}_{2} \mathrm{H}, \mathrm{CFH}_{2}, \mathrm{CF}_{2} \mathrm{CF}_{2} \mathrm{H}, \mathrm{CF}_{2}{ }^{18} \mathrm{~F}
\end{array}
$$

\begin{tabular}{|ll|}
\hline 24 examples with $\geq 80 \%$ yield & $\checkmark$ electron rich and poor (hetero)aryl bromides \\
$\square$ short reaction duration & $\checkmark$ coupling with $\left[{ }^{18} \mathrm{~F}\right]$ trifluoroethanol
\end{tabular}

ABSTRACT: Herein, we report a highly effective protocol for the cross-coupling of (hetero)aryl bromides with fluorinated alcohols using the commercially available precatalyst ${ }^{\mathrm{t}} \mathrm{BuBrettPhos} \mathrm{Pd} \mathrm{G} 3$ and $\mathrm{Cs}_{2} \mathrm{CO}_{3}$ in toluene. This Pd-catalyzed coupling features a short reaction time, excellent functional group tolerance, and compatibility with electron-rich and -poor (hetero)arenes. The method provides access to ${ }^{18} \mathrm{~F}$-labeled trifluoroethyl ethers by cross-coupling with $\left[{ }^{18} \mathrm{~F}\right]$ trifluoroethanol.

$\mathrm{F}$ luorinated alkyl aryl ethers are encountered in medicinal chemistry and agrochemistry, due to the ability of fluorine to modulate molecular properties including lipophilicity and metabolic stability. ${ }^{1}$ Prominent molecules featuring these motifs include the multibillion-dollar proton pump inhibitor lansoprazole, the antiarrhythmic flecainide, and idalopirdine (Figure 1). Approaches for fluoroalkyl aryl ether preparation

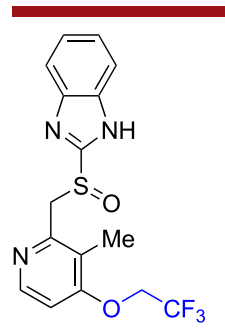

lansoprazole

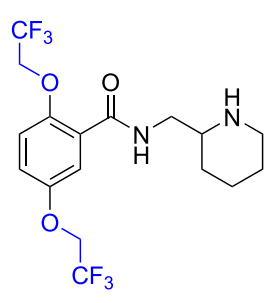

flecainide

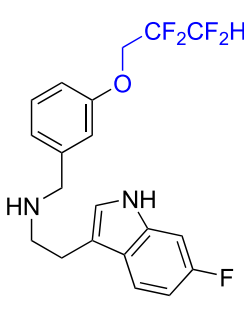

idalopirdine
Figure 1. Drugs containing fluorinated alkyl aryl ethers.

include Chan-Lam coupling of aryl boronic acids, ${ }^{2,3}$ Williamson ether synthesis, ${ }^{4}$ and transition metal mediated cross-coupling of aryl halides with fluorinated alcohols. ${ }^{5-8}$ Copper mediated approaches include coupling of fluorinated alcohols with aryl iodides under copper catalysis reported by Bonnet-Delpon and co-workers ${ }^{5}$ and reaction of aryl bromides with a copper(I) fluoroalkoxide complex reported by the Weng group. ${ }^{8}$ The Singh group has reported palladium-catalyzed coupling of fluorinated alcohols with aryl bromides bearing para-electron-withdrawing groups. ${ }^{6,7}$ Limitations of these protocols include the use of stoichiometric transitions metals $(\mathrm{Cu}(\mathrm{I})$ fluoroalkoxide procedure $),{ }^{8}$ limited substrate scope (Pd-catalyzed procedure), long reaction times, and/or the requirement of neat fluorinated alcohols $(\mathrm{Cu}$-catalyzed procedure). ${ }^{5}$

Shekhar and co-workers reported novel biaryl phosphorinane ligands for $\mathrm{Pd}$-catalyzed $\mathrm{C}-\mathrm{O}$ cross-coupling with electron-rich and heteroaryl halides, but these ligands are currently not commercially available. ${ }^{9}$ In this field of research, the contribution of Buchwald and co-workers stands out by providing an excellent procedure for $\mathrm{C}-\mathrm{O}$ cross-coupling of alcohols and aryl halides in the presence of $\mathrm{NaO}^{t} \mathrm{Bu}$ in dioxane and using commercially available precatalysts ${ }^{t} \mathrm{BuBrett} P$ hos $\mathrm{Pd}$ G3 and AdCyBrettPhos Pd G3. ${ }^{10}$ For alcohols of reduced nucleophilicity including 2,2,2-trifluoroethanol and 2,2,3,3,3pentafluoropropanol, superior yields were obtained using AdCyBrettPhos Pd G3.

Given our interest in narrowing the gap between ${ }^{19} \mathrm{~F}$ - and ${ }^{18} \mathrm{~F}$-chemistry, ${ }^{11-14}$ we considered applying this $\mathrm{C}-\mathrm{O}$ crosscoupling as a radiosynthetic route to install ${ }^{18} \mathrm{~F}$-labeled fluorinated alkyl aryl ethers motifs. For this purpose, it was necessary to adapt the protocol to accommodate short reaction

Received: July 14, 2020

Published: August 4, 2020 
times $\left({ }^{18} \mathrm{~F}\right.$ half-life $\left.=109.7\right)$. In addition, it is important that no large excess of fluorinated alcohol is required for effective coupling considering that cyclotron-produced ${ }^{18} \mathrm{~F}$-fluoride is available in the picomolar range. Herein, we report the $\mathrm{Pd}$ catalyzed $\mathrm{C}-\mathrm{O}$ coupling of fluorinated alcohols using ${ }^{t} \mathrm{Bu}-$ BrettPhos Pd G3 with the mild base $\mathrm{Cs}_{2} \mathrm{CO}_{3}$ in toluene. This protocol accommodates an extensive range of (hetero)aryl bromide and fluorinated alcohols and was adapted for crosscoupling with $\left[{ }^{18} \mathrm{~F}\right]$ trifluoroethanol.

We investigated the Pd-catalyzed cross-coupling reaction between trifluoroethanol and 1a, a demanding aryl bromide considering the lack of an activating electron-withdrawing group attached directly to the aromatic ring, and the presence of mildly acidic protons $\alpha$ to the ketone (Table 1 ). We

Table 1. Reaction Optimization

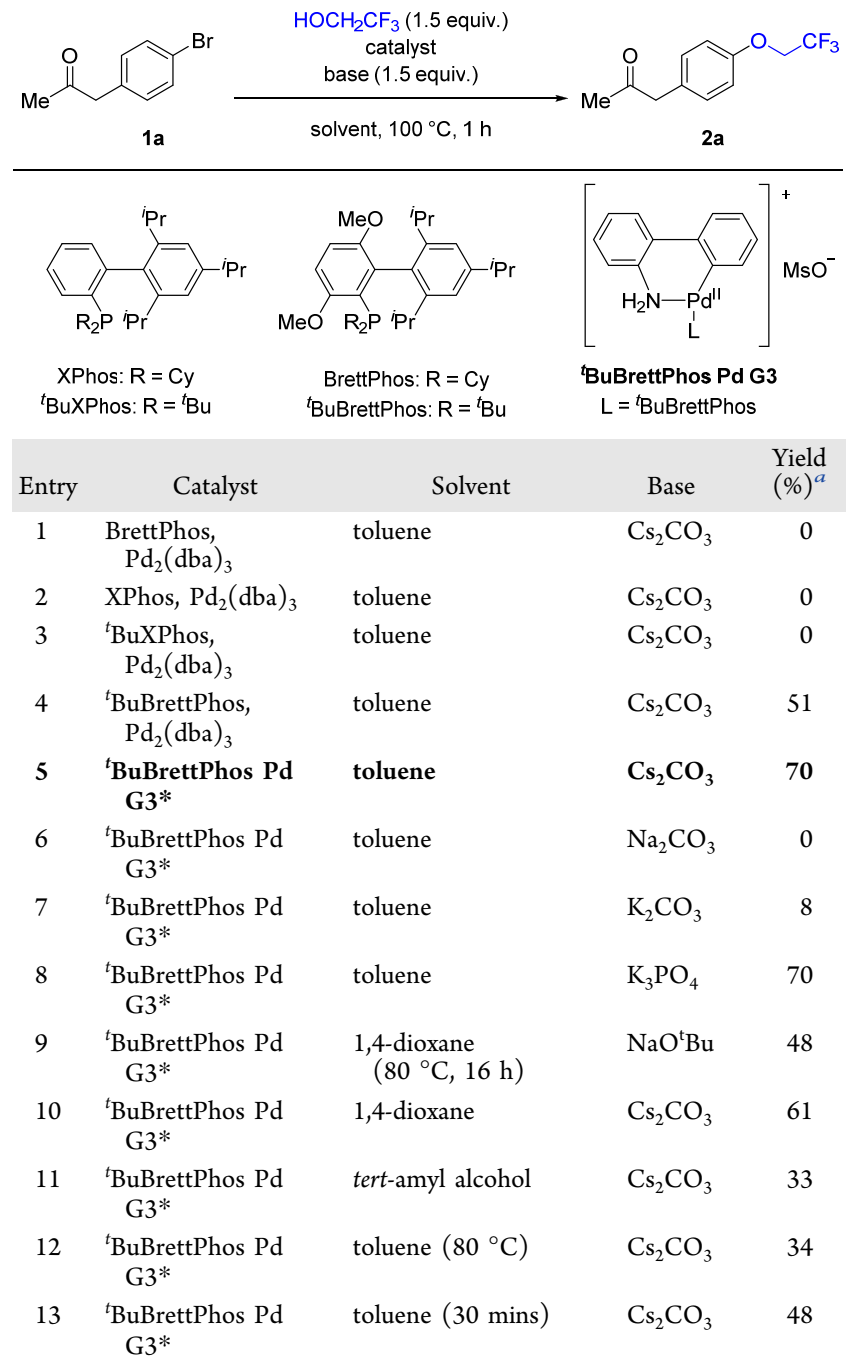

${ }^{a}$ Yields determined by ${ }^{19} \mathrm{~F}$ qNMR with $\mathrm{PhCF}_{3}$ as internal standard. For entries 1-4, $0.5 \mathrm{~mol} \%$ of $\mathrm{Pd}_{2}(\mathrm{dba})_{3}$ and $1.25 \mathrm{~mol} \%$ of ligand were used. For entries $6-13,1 \mathrm{~mol} \%$ of the precatalyst was used.

screened short reaction durations with the foresight of applying the coupling for introducing ${ }^{18} \mathrm{~F}$-labeled motifs. Under conditions similar to those reported by Singh, using BrettPhos, $\mathrm{Pd}_{2}(\mathrm{dba})_{3}$, and $\mathrm{Cs}_{2} \mathrm{CO}_{3}$ in toluene, no coupled product was formed after $1 \mathrm{~h}$ (entry 1$){ }^{6}$ Switching the ligand to either $\mathrm{XPhos}$ or ${ }^{t} \mathrm{BuXPhos}$ also resulted in no product formation (entries 2 and 3). ${ }^{15,16}$ Using ${ }^{t} \mathrm{BuBrettPhos}$ as ligand, the coupled product was observed in $51 \%$ yield (entry 4 ). An increase to $70 \%$ yield was observed using Buchwald's ${ }^{t} \mathrm{Bu}$ BrettPhos Pd G3 precatalyst (entry 5). Buchwald's precatalysts are air and moisture stable $\mathrm{Pd}(\mathrm{II})$-palladacycles, which allow for quantitative formation of the catalytically active $\operatorname{LPd}(0)$ species in situ following base induced $\mathrm{C}-\mathrm{N}$ reductive elimination. ${ }^{17} \mathrm{Cs}_{2} \mathrm{CO}_{3}$ gave superior results compared to both sodium and potassium carbonate (entries 6 and 7). $\mathrm{K}_{3} \mathrm{PO}_{4}$ was an effective base, affording the product in $70 \%$ yield (entry 8). While $\mathrm{Cs}_{2} \mathrm{CO}_{3}$ was used for this study, use of $\mathrm{K}_{3} \mathrm{PO}_{4}$ may be advantageous on a larger scale, as it is significantly cheaper than $\mathrm{Cs}_{2} \mathrm{CO}_{3}$. The use of $\mathrm{NaO}^{t} \mathrm{Bu}$ as base with 1,4-dioxane as solvent ${ }^{10}$ resulted in a reduced yield (entry 9). While stronger bases such as $\mathrm{NaO}^{t} \mathrm{Bu}$ can promote $\mathrm{C}-\mathrm{O}$ cross-couplings at lower temperatures than weaker inorganic bases such as $\mathrm{Cs}_{2} \mathrm{CO}_{3}$, they can also lead to reduced yields for base-sensitive substrates. ${ }^{18,19}$ Toluene afforded a higher yield than 1,4-dioxane (entry 10) and tert-amyl alcohol (entry 11). Reducing the reaction duration to $30 \mathrm{~min}$ or the temperature to $80{ }^{\circ} \mathrm{C}$ resulted in lower yields (entries 12 and 13 ).

The scope of the reaction with respect to the aryl bromide was explored next (Scheme 1). Various electron-rich aryl bromides underwent coupling with trifluoroethanol in high yield after 0.5 to $2 \mathrm{~h}$, with morpholinyl and methoxy substitution well tolerated ( $2 \mathbf{b}$ to $\mathbf{2 d}$ ). Product $\mathbf{2 c}$ was isolated in $89 \%$ yield, while it has been reported to form in $69 \%$ NMR yield using $\mathrm{NaO}^{t} \mathrm{Bu}$ and 1,4-dioxane. ${ }^{10}$ The reaction conditions were applied to the double $\mathrm{C}-\mathrm{O}$ cross-coupling of 1,4dibromobenzene to yield $\mathbf{2} \mathrm{f}$ in a single step. Electron-deficient aryl bromides also underwent coupling in excellent yields (substrates $\mathbf{2 h}$ to $\mathbf{2 k}$ ). A wide range of functional groups were well tolerated including sulfone, ester, ketone, aldehyde, and nitro groups, some bearing acidic $\alpha$-protons. For many substrates, the reaction temperature could be decreased to $80{ }^{\circ} \mathrm{C}$ without detrimental impact on reactivity. In contrast, when electron-rich aryl bromides such as $\mathbf{1 d}$ were reacted with trifluoroethanol at $80{ }^{\circ} \mathrm{C}$, starting material was recovered almost quantitatively. Heteroaryl bromides also underwent coupling $(\mathbf{2 n - 2 r})$, with $80{ }^{\circ} \mathrm{C}$ being adequate for some substrates. Pyridines, pyrimidine, quinoline, and quinoxaline substrates all coupled effectively. This cross-coupling method was applied to prepare the drug precursor $N$-Boc-flecainide $(2 \mathrm{t})$.

Aryl chlorides were also investigated as substrates. The activated aryl chloride fenofibrate $\mathbf{1 v}$ underwent $\mathrm{C}-\mathrm{O}$ crosscoupling in excellent yield. A control experiment excluding ${ }^{t}$ BuBrettPhos Pd G3 afforded no product, ruling out a nucleophilic aromatic substitution mechanism. Contrarily, electron-rich aryl chloride $\mathbf{1 b}(\mathrm{Cl})$ afforded only traces of the coupled product. For preparing compounds $2 \mathbf{a}, \mathbf{2} \mathbf{u}$, and $\mathbf{2 w}$, the conditions reported herein were compared directly to use of $\mathrm{NaO}^{t} \mathrm{Bu}$ with 1,4-dioxane (NMRY for conditions herein vs $\mathrm{NMRY}^{*}$ for $\mathrm{NaO}^{t} \mathrm{Bu}$ conditions, Scheme 1$) .{ }^{10}$ In these cases, higher yields were observed using $\mathrm{Cs}_{2} \mathrm{CO}_{3}$ and toluene.

Various other fluorinated alcohols were successfully coupled to aryl bromides under our optimized conditions. Notably, in contrast to 2,2,2-trifluoroethanol, coupling reactions of electron-rich aryl bromides with 2,2-difluoroethanol could be carried out at $80{ }^{\circ} \mathrm{C}$. Furthermore, electron-poor aryl bromides and heteroaryl bromides successfully coupled with 2,2difluoroethanol. 2-Fluoroethanol also reacted in high yield (4d). In a competition experiment in which equimolar quantities of 2,2,2-trifluorethanol, 2,2-difluoroethanol, and 2- 
Scheme 1. Pd-Catalyzed C-O Cross-Coupling of Fluorinated Alcohols with Aryl Bromides (Yields of Isolated Products Are Quoted)
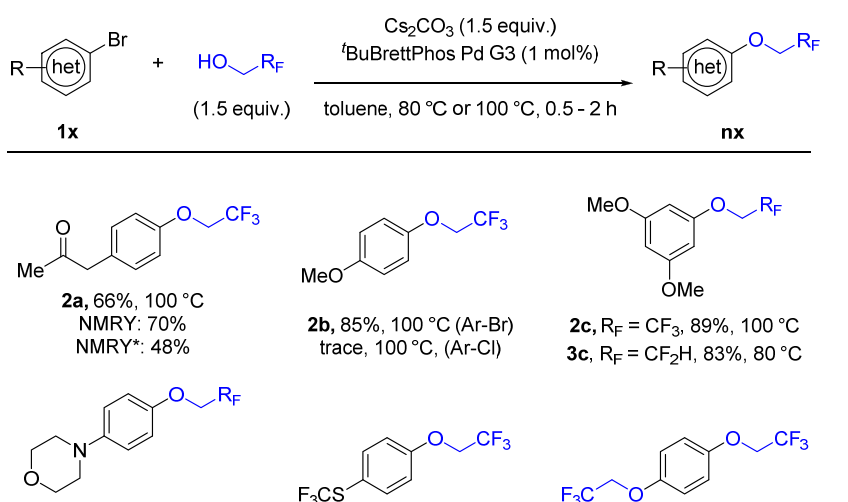

2b, $85 \%, 100^{\circ} \mathrm{C}$ (Ar-Br) trace, $100^{\circ} \mathrm{C},(\mathrm{Ar}-\mathrm{Cl})$

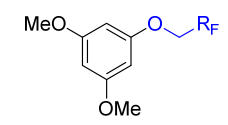

2c, $\mathrm{R}_{\mathrm{F}}=\mathrm{CF}_{3}, 89 \%, 100^{\circ} \mathrm{C}$ $3 \mathrm{c}, \mathrm{R}_{\mathrm{F}}=\mathrm{CF}_{2} \mathrm{H}, 83 \%, 80^{\circ} \mathrm{C}$ 2d, $\mathrm{R}_{\mathrm{F}}=\mathrm{CF}_{3}, 80 \%, 100^{\circ} \mathrm{C}$ 3d, $\mathrm{R}_{\mathrm{F}}=\mathrm{CF}_{2} \mathrm{H}, 87 \%, 80^{\circ} \mathrm{C}$

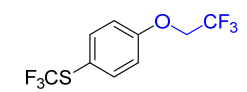

$2 \mathrm{e}, 83 \%, 80^{\circ} \mathrm{C}$<smiles>COC(=O)c1ccc2cc(OCC(F)(F)F)ccc2c1</smiles>

$2 \mathrm{~h}, 93 \%, 80^{\circ} \mathrm{C}$

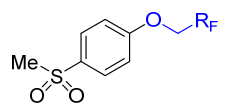

2k, $\mathrm{R}_{\mathrm{F}}=\mathrm{CF}_{3}, 87 \%, 80^{\circ} \mathrm{C}$ 3k, $\mathrm{R}_{\mathrm{F}}=\mathrm{CF}_{2} \mathrm{H}, 90 \%, 80^{\circ} \mathrm{C}$<smiles>FCOc1cncnc1</smiles>

$2 \mathrm{~m}, 95 \%, 80^{\circ} \mathrm{C}$

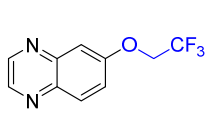

2p, $99 \%$ b $80^{\circ} \mathrm{C}$<smiles>FC(F)(F)COc1cccc(C(F)(F)F)c1</smiles><smiles>CC(C)(C)OC(=O)c1ccc(OCC(F)(F)F)cc1C(=O)NCC1CCCCC1(C(F)(F)F)C(F)(F)F</smiles>

2s, $80 \%, 80^{\circ} \mathrm{C}$ 2n, $\mathrm{R}_{\mathrm{F}}=\mathrm{CF}_{3}, 90 \%, 100^{\circ} \mathrm{C}$ 3n, $R_{F}=\mathrm{CF}_{2} \mathrm{H}, 92 \%, 80^{\circ} \mathrm{C}$<smiles>FC(F)(F)COc1cnc2ccccc2c1</smiles>

2q, $90 \%, 80^{\circ} \mathrm{C}$

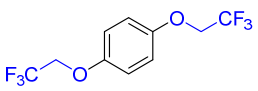

2f, $76 \%$, $100^{\circ} \mathrm{C}$

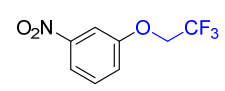

2i, $87 \%, 80^{\circ} \mathrm{C}$

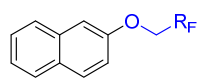

21, $\mathrm{R}_{\mathrm{F}}=\mathrm{CF}_{3}, 85 \%, 80^{\circ} \mathrm{C}$

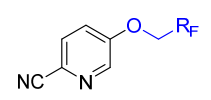

2o, $\mathrm{R}_{\mathrm{F}}=\mathrm{CF}_{3}, 93 \%, 80^{\circ} \mathrm{C}$ 3o, $R_{F}=\mathrm{CF}_{2} \mathrm{H}, 73 \%, 80^{\circ} \mathrm{C}$

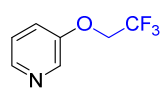

$2 r, 43 \%,{ }^{c} 100^{\circ} \mathrm{C}$ 3I, $R_{F}=\mathrm{CF}_{2} \mathrm{H}, 92 \%, 80^{\circ} \mathrm{C}$<smiles>O=Cc1cccc(OCC(F)(F)F)c1</smiles>
2t, $38 \%, 100^{\circ} \mathrm{C}$
$N$-Boc-flecainide<smiles>CC(C)OC(=O)C(C)(C)Oc1ccc(C(=O)c2ccc(OCC(F)(F)F)cc2)cc1</smiles>

$$
\text { 2v, 93\%, } 100^{\circ} \mathrm{C} \text { (Ar-Cl, fenofibrate) }
$$
$\mathrm{S}_{\mathrm{N}} \mathrm{Ar}$ control with no 'Pd', $0 \%$

$a_{2}$ mol \% ${ }^{t}$ BuBrettPhos Pd G3, 3 equiv of $\mathrm{Cs}_{2} \mathrm{CO}_{3}$ and trifluoroethanol used. ${ }^{b}$ Yield determined by ${ }^{19} \mathrm{~F}$ qNMR. ${ }^{c}$ Reaction duration of $4 \mathrm{~h}$. NMRY $=$ NMR yield under the conditions reported herein. $\mathrm{NMRY}^{*}=\mathrm{NMR}$ yield using $\mathrm{NaO}^{t} \mathrm{Bu}$ in 1,4-dioxane at 40 to $80{ }^{\circ} \mathrm{C}$.

fluoroethanol were reacted with substrate $1 \mathrm{~d}$ at $100{ }^{\circ} \mathrm{C}$ for $2 \mathrm{~h}$ under the conditions reported herein, the trifluoroethyl, difluoroethyl, and fluoroethyl ethers were formed in an $\sim$ 1:3:2 ratio, respectively. This supports decreased reactivity of 2,2,2-trifluoroethanol relative to 2,2-difluoroethanol and 2fluoroethanol.

The scalability of the $\mathrm{C}-\mathrm{O}$ cross-coupling reaction was demonstrated by the gram-scale coupling of 2,2,3,3-tetrafluoropropanol and 3-bromobenzaldehyde for the preparation of $2 \mathbf{u}$, an intermediate in the synthesis of the drug idalopirdine (Figure 1). ${ }^{20}$ For this scale-up, the catalyst loading was reduced to $0.5 \mathrm{~mol} \%$ without impacting the yield of isolated product. On a larger scale, use of $\mathrm{Pd}_{2}(\mathrm{dba})_{3}$ with $\mathrm{tBuBrettPhos}$ rather than ${ }^{t} \mathrm{BuBrettPhos} \mathrm{Pd} \mathrm{G} 3$, and $\mathrm{K}_{3} \mathrm{PO}_{4}$ rather than $\mathrm{Cs}_{2} \mathrm{CO}_{3}$, may be preferable to reduce costs.

The short reaction time and high efficiency of incorporation of the fluorinated alcohol encouraged the use of this crosscoupling reaction for the introduction of ${ }^{18} \mathrm{~F}$-labeled motifs, specifically $\left[{ }^{18} \mathrm{~F}\right]$ trifluoroethanol (Scheme $2 \mathrm{~A}$ ). Preparation of

Scheme 2. (A) Approaches to $\left[{ }^{18} \mathrm{~F}\right]$ Trifluoroethyl Ethers; (B) Previously Reported Synthesis of $\left[{ }^{18} \mathrm{~F}\right]$ Trifluoroethanol Requiring Multiple Distillations and $\mathrm{AlH}_{3}$; (C) Our Approach for the Synthesis of $\left[{ }^{18} \mathrm{~F}\right]$ Trifluoroethanol; (D) Coupling of Aryl Bromides with $\left[{ }^{18} \mathrm{~F}\right]$ Trifluoroethanol

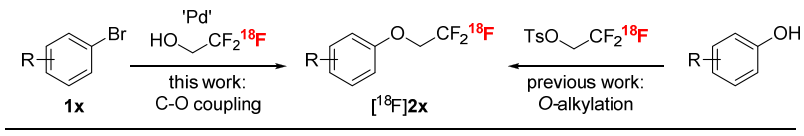

B.

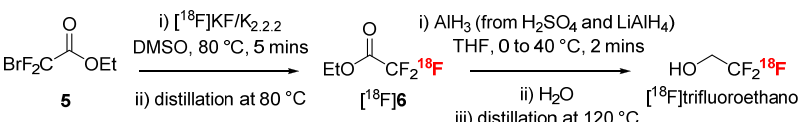

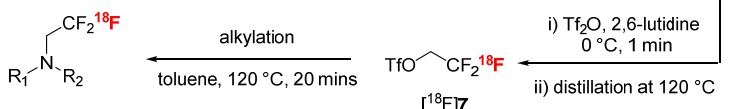

$$
\begin{aligned}
& \text { c. } \mathrm{R}=\mathrm{Me}_{\mathrm{Me}}^{\mathrm{Me}}>\mathrm{Me}
\end{aligned}
$$

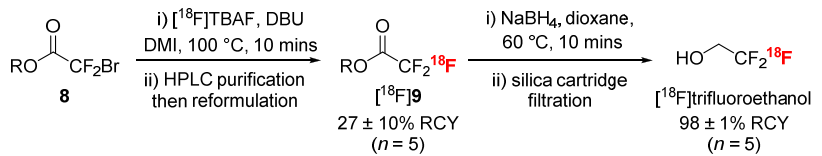

$D$.

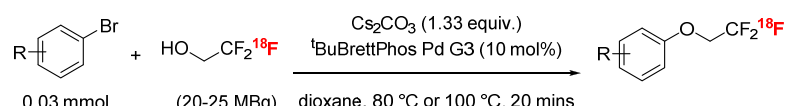

$$
\begin{aligned}
& \text { 1a, } 1 \text { [ } \quad\left[{ }^{18} \mathrm{~F}\right] 2 \mathrm{a},\left[{ }^{18} \mathrm{~F}\right] 2 ! \\
& \text {. }
\end{aligned}
$$
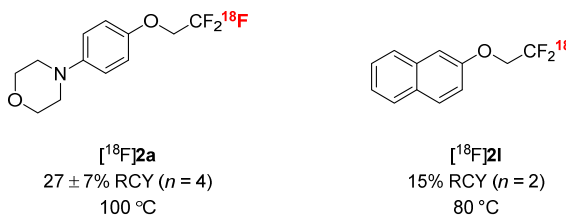

${ }^{a} \mathrm{RCY}=$ radiochemical yield, determined by integration of the radioHPLC trace (prior to HPLC for compound 9).

an ${ }^{18} \mathrm{~F}$-trifluoroethyl ether has been reported by the Riss group via alkylation of the corresponding phenol with $\left[{ }^{18} \mathrm{~F}\right]$ trifluoroethyl tosylate (Scheme $2 \mathrm{~A}$ ). ${ }^{21-24}$ Here, we propose a complementary approach that utilizes a $\mathrm{C}-\mathrm{O}$ cross-coupling event to prepare ${ }^{18} \mathrm{~F}$-trifluoroethyl ethers $\left[{ }^{18} \mathrm{~F}\right] 2$ from aryl bromides and $\left[{ }^{18} \mathrm{~F}\right]$ trifluoroethanol. $\left[{ }^{18} \mathrm{~F}\right]$ Trifluoroethanol has 
previously been synthesized by nucleophilic radiofluorination of ethyl bromodifluoroacetate 5 with $\left[{ }^{18} \mathrm{~F}\right] \mathrm{KF} / \mathrm{K}_{2.2 .2}$, followed by reduction with $\mathrm{AlH}_{3}$ prepared in situ from $\mathrm{LiAlH}_{4}$ and $\mathrm{H}_{2} \mathrm{SO}_{4}$ (Scheme $2 \mathrm{~B}$ ). ${ }^{25}$ The $\left[{ }^{18} \mathrm{~F}\right]$ trifluoroethanol was not used directly and required an additional step to generate $\left[{ }^{18} \mathrm{~F}\right]$ trifluoroethyl triflate, which was then applied for amine alkylation. Multiple distillations were used to purify ethyl $\left[{ }^{18} \mathrm{~F}\right]$ trifluoroacetate 7 and $\left[{ }^{18} \mathrm{~F}\right]$ trifluoroethanol.

We sought to develop an $\left[{ }^{18} \mathrm{~F}\right]$ trifluoroethanol synthesis without distillation, using instead HPLC purification. We also aimed to replace $\mathrm{AlH}_{3}$ with $\mathrm{NaBH}_{4}$, a reducing agent readily available and easy to handle. Our initial experiments showed that ethyl trifluoroacetate $\left[{ }^{18} \mathrm{~F}\right] 6$ is unstable under reversedphase HPLC conditions. Therefore, we targeted menthol $\left[{ }^{18} \mathrm{~F}\right]$ trifluoroacetate $\left[{ }^{18} \mathrm{~F}\right] \mathbf{9}$, an ester which is more resistant to hydrolysis and therefore amenable to purification by reversedphase HPLC (Scheme 2C). Under conditions slightly modified from those previously reported by Szabó and Schou, ${ }^{26}$ synthesis of $\left[{ }^{18} \mathrm{~F}\right] 9$ was achieved in $27 \pm 10 \%$ radiochemical yield (RCY) using $\left[{ }^{18} \mathrm{~F}\right]$ TBAF and DBU in 1,3-dimethyl-2imidazolidinone (DMI). ${ }^{27}$ After HPLC purification and reformulation into 1,4-dioxane, reduction using $\mathrm{NaBH}_{4}$ afforded $\left[{ }^{18} \mathrm{~F}\right]$ trifluoroethanol in $98 \pm 1 \% \mathrm{RCY}$. Menthol, formed during the reduction step, was found to be unreactive under the conditions applied for $\mathrm{C}-\mathrm{O}$ cross-coupling, and therefore a purification step by filtration to remove salts was sufficient. 1,4-Dioxane was used as the reaction solvent, as it afforded high yields for the reduction (toluene performed poorly) and proved highly suitable for the subsequent $\mathrm{C}-\mathrm{O}$ cross-coupling (Table 1, entry 10). This modification was advantageous by avoiding a second reformulation step.

Under slightly modified coupling conditions, $\left[{ }^{18} \mathrm{~F}\right]$ trifluoroethanol was coupled with aryl bromide $\mathbf{1 a}$ and naphthyl bromide $\mathbf{1 1}$ to afford the desired cross-coupled $\left[{ }^{18} \mathrm{~F}\right]$ trifluoroethyl ethers (Scheme 2D). Radio-HPLC showed clean reaction profiles, with mainly the ${ }^{18} \mathrm{~F}$-labeled product and unreacted $\left[{ }^{18} \mathrm{~F}\right]$ trifluoroethanol. Extending the reaction duration beyond 20 minutes did not increase the RCY. Our study showed that the coupling was sensitive to the water content in the $\left[{ }^{18} \mathrm{~F}\right]$ trifluoroethanol solution; drying of menthol $\left[{ }^{18} \mathrm{~F}\right]$ trifluoroacetate $\left[{ }^{18} \mathrm{~F}\right] \mathbf{9}$ under a flow of nitrogen was essential prior to reformulation in 1,4-dioxane. ${ }^{27}$ While Pdmediated $\mathrm{C}-\mathrm{N}$ and $\mathrm{C}-\mathrm{C}$ cross-coupling has been used for introduction of ${ }^{18} \mathrm{~F}$-labeled motifs, ${ }^{28}$ this work supports the feasibility of ${ }^{18} \mathrm{~F}$-radiolabeling by $\mathrm{Pd}$-mediated $\mathrm{C}-\mathrm{O}$ crosscoupling.

In conclusion, we have developed a protocol for Pdcatalyzed cross-coupling between fluorinated alcohols and (hetero)aryl bromides using the mild base $\mathrm{Cs}_{2} \mathrm{CO}_{3}$; the reaction tolerates various electronic patterns on the arene ring, a wide range of functional groups including those with mildly acidic $\alpha$-protons, and proceeds over a short duration. An activated aryl chloride has also been shown to couple effectively. In addition, $\mathrm{K}_{3} \mathrm{PO}_{4}$ was found to be a cheaper alternative base to $\mathrm{Cs}_{2} \mathrm{CO}_{3}$. The utility of the coupling has been further demonstrated with a new disconnection approach to ${ }^{18} \mathrm{~F}$-labeled trifluoroethyl ethers consisting of $\mathrm{C}-\mathrm{O}$ crosscoupling of aryl bromides with $\left[{ }^{18} \mathrm{~F}\right]$ trifluoroethanol.

\section{ASSOCIATED CONTENT}

\section{Supporting Information}

The Supporting Information is available free of charge at https://pubs.acs.org/doi/10.1021/acs.orglett.0c02347.

Experimental data, characterization data, ${ }^{18} \mathrm{~F}$-radiotraces (PDF)

\section{AUTHOR INFORMATION}

\section{Corresponding Author}

Véronique Gouverneur - Chemistry Research Laboratory, Oxford University, Oxford OX1 3TA, U.K.; 이이.org/ 0000-0001-8638-5308; Email: veronique.gouverneur@ chem.ox.ac.uk

\section{Authors}

Robert Szpera - Chemistry Research Laboratory, Oxford University, Oxford OX1 3TA, U.K.

Patrick G. Isenegger - Chemistry Research Laboratory, Oxford University, Oxford OX1 3TA, U.K.

Maxime Ghosez - Chemistry Research Laboratory, Oxford University, Oxford OX1 3TA, U.K.

Natan J. W. Straathof - Chemistry Research Laboratory, Oxford University, Oxford OX1 3TA, U.K.

Rosa Cookson - Medicines Research Centre, GlaxoSmithKline plc, Stevenage, Hertfordshire SG1 2NY, U.K.

David C. Blakemore - Medicine Design, Pfizer Inc., Groton Connecticut 06340, United States

Paul Richardson - Medicine Design, Pfizer Inc., San Diego, California 92121, United States

Complete contact information is available at:

https://pubs.acs.org/10.1021/acs.orglett.0c02347

\section{Notes}

The authors declare no competing financial interest.

\section{ACKNOWLEDGMENTS}

We acknowledge the EPSRC Centre for Doctoral Training in Synthesis for Biology and Medicine (EP/L015838/1) for a studentship to R.S. (Oxford University), generously supported by AstraZeneca, Diamond Light Source, Defence Science and Technology Laboratory, Evotec, GlaxoSmithKline, Janssen, Novartis, Pfizer, Syngenta, Takeda, UCB, and Vertex. We also acknowledge the Swiss National Foundation (P2BSP2_178609, P.G.I., Oxford University), ERASMUS (M.G., Oxford University), and the EPSRC (EP/R511742/1, N.J.W.S., Oxford University) for funding. We acknowledge Jeroen B. I. Sap (Oxford University) and Florian Guibbal (Oxford University) for assistance with radiochemical experiments. We also acknowledge Stephen Hyde (Oxford University) for conducting preliminary experiments, Adeline W. J. Poh (Oxford University) for synthesizing an intermediate, and Eddie Toma (Oxford University) for assistance using the glovebox.

\section{REFERENCES}

(1) Irurre, J.; Casas, J.; Messeguer, A. Resistance of the 2,2,2Trifluoroethoxy Aryl Moiety to the Cytochrome P-450 Metabolism in Rat Liver Microsomes. Bioorg. Med. Chem. Lett. 1993, 3 (2), 179182.

(2) Wang, R.; Wang, L.; Zhang, K.; Li, J.; Zou, D.; Wu, Y.; Wu, Y. Facile Synthesis of Trifluoroethyl Aryl Ethers through Copper- 
Catalyzed Coupling of $\mathrm{CF}_{3} \mathrm{CH}_{2} \mathrm{OH}$ with Aryl- and Heteroaryl Boronic Acids. Tetrahedron Lett. 2015, 56 (33), 4815-4818.

(3) Zhang, K.; Xu, X.-H.; Qing, F.-L. Copper-Catalyzed Oxidative Trifluoroethoxylation of Aryl Boronic Acids with $\mathrm{CF}_{3} \mathrm{CH}_{2} \mathrm{OH}$. J. Fluorine Chem. 2017, 196, 24-31.

(4) Kamal, A.; Pratap, T.; Ramana, K. V.; Ramana, A.; Babu, A. H. Facile and Efficient Synthesis of Fluoroalkyl Aryl Ethers. Tetrahedron Lett. 2002, 43 (41), 7353-7355.

(5) Vuluga, D.; Legros, J.; Crousse, B.; Bonnet-Delpon, D. Facile Access to Fluorinated Aryl and Vinyl Ethers through CopperCatalysed Reaction of Fluoro Alcohols. Eur. J. Org. Chem. 2009, 2009, 3513-3518.

(6) Rangarajan, T. M.; Singh, R.; Brahma, R.; Devi, K.; Singh, R. P.; Singh, R. P.; Prasad, A. K. BrettPhos Ligand Supported PalladiumCatalyzed C-O Bond Formation through an Electronic Pathway of Reductive Elimination: Fluoroalkoxylation of Activated Aryl Halides. Chem. - Eur. J. 2014, 20 (44), 14218-14225.

(7) Rangarajan, T. M.; Devi, K.; Ayushee; Prasad, A. K.; Pal Singh, R. A General, Mild and Efficient Palladium-Catalyzed 2,2,2Trifluoroethoxylation of Activated Aryl Bromides and BromoChalcones: Bromo-Chalcones a New Coupling Partner in CrossCoupling Reaction. Tetrahedron 2015, 71 (43), 8307-8314.

(8) Huang, R.; Huang, Y.; Lin, X.; Rong, M.; Weng, Z. Well-Defined Copper(I) Fluoroalkoxide Complexes for Trifluoroethoxylation of Aryl and Heteroaryl Bromides. Angew. Chem., Int. Ed. 2015, 54 (19), 5736-5739.

(9) Laffoon, S. D.; Chan, V. S.; Fickes, M. G.; Kotecki, B.; Ickes, A. R.; Henle, J.; Napolitano, J. G.; Franczyk, T. S.; Dunn, T. B.; Barnes, D. M.; Haight, A. R.; Henry, R. F.; Shekhar, S. Pd-Catalyzed CrossCoupling Reactions Promoted by Biaryl Phosphorinane Ligands. ACS Catal. 2019, 9 (12), 11691-11708.

(10) Zhang, H.; Ruiz-Castillo, P.; Buchwald, S. L. PalladiumCatalyzed C-O Cross-Coupling of Primary Alcohols. Org. Lett. 2018, 20 (6), 1580-1583.

(11) Buckingham, F.; Kirjavainen, A. K.; Forsback, S.; Krzyczmonik, A.; Keller, T.; Newington, I. M.; Glaser, M.; Luthra, S. K.; Solin, O.; Gouverneur, V. Organomediated Enantioselective ${ }^{18} \mathrm{~F}$ Fluorination for PET Applications. Angew. Chem., Int. Ed. 2015, 54 (45), 1336613369.

(12) Taylor, N. J.; Emer, E.; Preshlock, S.; Schedler, M.; Tredwell, M.; Verhoog, S.; Mercier, J.; Genicot, C.; Gouverneur, V. Derisking the Cu-Mediated ${ }^{18}$ F-Fluorination of Heterocyclic Positron Emission Tomography Radioligands. J. Am. Chem. Soc. 2017, 139 (24), 82678276.

(13) Teare, H.; Robins, E. G.; Årstad, E.; Luthra, S. K.; Gouverneur, $\mathrm{V}$. Synthesis and Reactivity of $\left[{ }^{18} \mathrm{~F}\right]-\mathrm{N}$-Fluorobenzenesulfonimide. Chem. Commun. 2007, 23, 2330-2332.

(14) Khotavivattana, T.; Verhoog, S.; Tredwell, M.; Pfeifer, L.; Calderwood, S.; Wheelhouse, K.; Lee Collier, T.; Gouverneur, V. ${ }^{18} \mathrm{~F}$ Labeling of Aryl- $\mathrm{SCF}_{3},-\mathrm{OCF}_{3}$ and $-\mathrm{OCHF}_{2}$ with $\left[{ }^{18} \mathrm{~F}\right]$ Fluoride. Angew. Chem., Int. Ed. 2015, 54 (34), 9991-9995.

(15) Reeta; Rangarajan, T. M.; Ayushee; Singh, R. P.; Singh, R. P. Palladium-Catalyzed Rapid Methoxylation and Deuteriomethoxylation of Bromo-Chalcones: Uncovering the Catalytic Activity of the $\mathrm{Pd} / \mathrm{tBuXPhos}$ Catalyst System. ChemistrySelect 2016, 1 (21), 68946901.

(16) Rangarajan, T. M.; Devi, K.; Verma, A. K.; Singh, R. P.; Singh, R. P. A General and Efficient Pd-Catalyzed Rapid 2-Fluoroethoxylation of Bromo-Chalcones. J. Fluorine Chem. 2016, 186, 101-110. (17) Bruno, N. C.; Buchwald, S. L. Synthesis and Application of Palladium Precatalysts That Accommodate Extremely Bulky Di- Tert -Butylphosphino Biaryl Ligands. Org. Lett. 2013, 15 (11), 2876-2879.

(18) Buitrago Santanilla, A.; Christensen, M.; Campeau, L. C.; Davies, I. W.; Dreher, S. D. P2Et Phosphazene: A Mild, Functional Group Tolerant Base for Soluble, Room Temperature Pd-Catalyzed C-N, C-O, and C-C Cross-Coupling Reactions. Org. Lett. 2015, 17 (13), 3370-3373.
(19) Ingoglia, B. T.; Wagen, C. C.; Buchwald, S. L. Biaryl Monophosphine Ligands in Palladium-Catalyzed C-N Coupling: An Updated User's Guide. Tetrahedron 2019, 75 (32), 4199-4211.

(20) Jacobsen, M. F.; Nielsen, O. A Process for the Manufacture of Idalopirdine. WO 2016091997 A1, 2016.

(21) Riss, P. J.; Aigbirhio, F. I. A Simple, Rapid Procedure for Nucleophilic Radiosynthesis of Aliphatic $\left[{ }^{18} \mathrm{~F}\right]$ Trifluoromethyl Groups. Chem. Commun. 2011, 47 (43), 11873.

(22) Lien, V. T.; Riss, P. J. Radiosynthesis of $\left[{ }^{18} \mathrm{~F}\right]$ Trifluoroalkyl Groups: Scope and Limitations. BioMed Res. Int. 2014, 2014, 1.

(23) Riss, P. J.; Brichard, L.; Ferrari, V.; Williamson, D. J.; Fryer, T. D.; Hong, Y. T.; Baron, J.-C.; Aigbirhio, F. I. Radiosynthesis and Characterization of Astemizole Derivatives as Lead Compounds toward PET Imaging of $\tau$-Pathology. MedChem Comm 2013, 4 (5), 852.

(24) Riss, P. J.; Ferrari, V.; Brichard, L.; Burke, P.; Smith, R.; Aigbirhio, F. I. Direct, Nucleophilic Radiosynthesis of $\left[{ }^{18} \mathrm{~F}\right]$ Trifluoroalkyl Tosylates: Improved Labelling Procedures. Org. Biomol. Chem. 2012, 10 (34), 6980.

(25) Johnström, P.; Stone-Elander, S. The ${ }^{18}$ F-Labelled Alkylating Agent 2,2,2-Trifluoroethyl Triflate: Synthesis and Specific Activity. J. Labelled Compd. Radiopharm. 1995, 36 (6), 537-547.

(26) Gómez, A. B.; Cortés González, M. A.; Lübcke, M.; Johansson, M. J.; Halldin, C.; Szabó, K. J.; Schou, M. Efficient DBU Accelerated Synthesis of ${ }^{18} \mathrm{~F}$-Labelled Trifluoroacetamides. Chem. Commun. 2016, 52 (97), 13963-13966.

(27) See the Supporting Information for a full disscusion on the radiochemisty, including molar activity.

(28) Pretze, M.; Große-Gehling, P.; Mamat, C. Cross-Coupling Reactions as Valuable Tool for the Preparation of PET Radiotracers. Molecules 2011, 16 (2), 1129-1165. 